- 3 - o sots

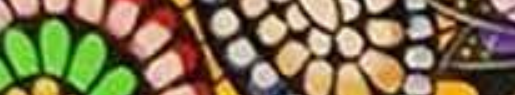
233 o 6 . 18 3. की 13 .

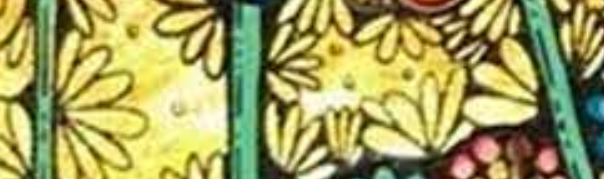
(n) of s. 808000 . . 065 3 . $8+63$ .

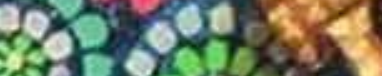

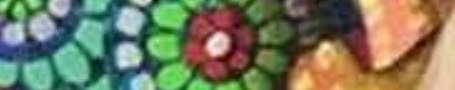
000 35

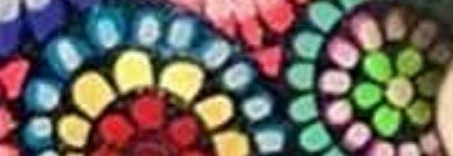

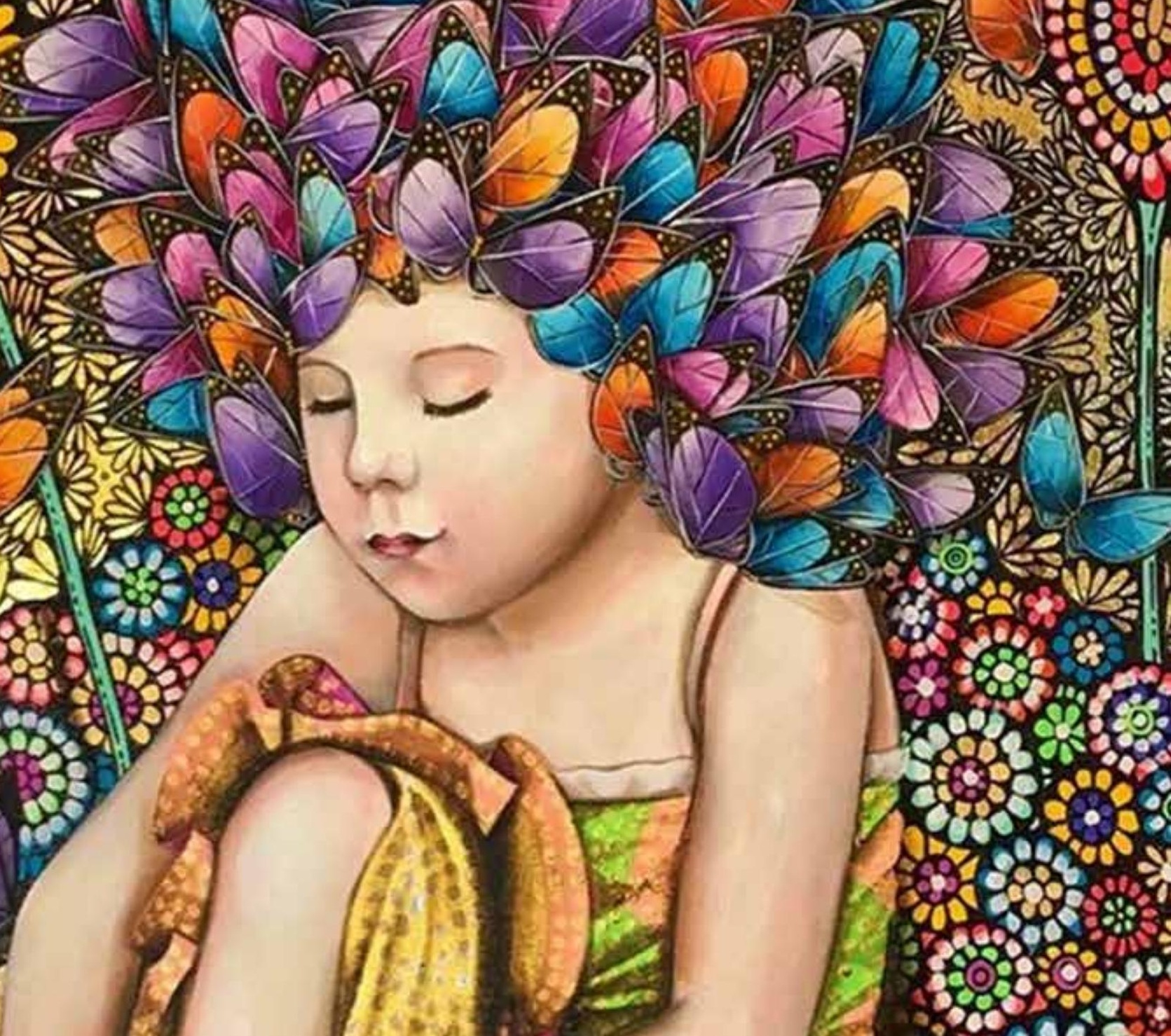




\section{RECUERDOS}

Quisiera tener palabras para expresar lo que siento y que se pueda leer lo que llevo en mis adentros

Porque le quiero decir a la tierra que más quiero, que si es grande la distancia más grandes son mis recuerdos.

Es a ti, Guadalajara, tú eres causa de mis versos, tú que me viste nacer allá, en un pueblo pequeño.

Yo recuerdo tus castillos que ya se caen de viejos sin que haya una mano amiga que haga nada por ellos.

Tenías ríos profundos, verdes, transparentes, bellos donde nadaban mayores, medianos y hasta pequeños

¿Y aquellos olmos altivos de las plazas de tus pueblos?

¡se los llevó la grafiosis! ¡pocos quedan de recuerdo!
¿Y aquellos hombres vestidos con un guardapolvo negro que vendían pez y miel y el aguardiente alcarreño?

$¿ Y$ aquellas mujeres guapas cual las más del universo? que no se moleste nadie, aquellas eran de acero.

Ayudaban en la siega, en la trilla y en el huerto el día de la matanza, era un día sin sosiego.

Cuidaban de los abuelos, de los padres y los suegros, de hermanos y del marido, después, de hijos y nietos.

Ellas bordaban cortinas, mantelerías y velos, trabajaban el mundillo, el ganchillo y el remiendo.

Guadalajara, tú tienes lo más grande, lo más bello solo me queda decirte: Guadalajara, te quiero 


\title{
1. Las nuevas centralidades gubernamentales de construcción de ciudad: caso de la Zona Metropolitana 23, Jalisco, México
}

\author{
Magdiel Gómez Muñiz ${ }^{1}$ \\ DOI: https://doi.org/10.5377/pdac.v16i0.10224
}

Recibido: 13/01/2020 - Aceptado: 21/01/2020

\begin{abstract}
Resumen: La consolidación de las agendas públicas intermunicipales en los municipios de México exigen discutir modelos de gestión para la construcción de ciudades a partir de acciones para la cooperación y acuerdos. El presente trabajo es el resultado de un estudio de caso de la Zona Metropolitana 23 constituida por los municipios de Ocotlán; Jamay y Poncitlán que se circunscriben en la Región Ciénega del Estado de Jalisco. Las ciudades y su metamorfosis facilitan el entendimiento -secuencial histórico- de lo importante que es que los presidentes municipales decidan a partir de estructuras parlamentarias comunes.
\end{abstract}

La metodología cualitativa implementada a través del análisis de caso concluye enunciativamente con seis costos que se deben considerar para hacer posible que el Instituto Metropolitano de Planeación como eje rector armonice los trabajos de los municipios respetando la soberanía de cada uno de ellos.

Palabras clave: ciudad; desarrollo; democracia; gobernabilidad; Zona Metropolitana.

\section{The new city planning of joined municipalities: case of the 23rd Metropolitan Zone in Jalisco, Mexico}

\begin{abstract}
The consolidation of the public schedule of intermunicipalities in Mexico demands the dialogue on the proposals for the construction of cities based on cooperation and the pursuit of middle grounds. The article is the result of case studies on the 23rd Metropolitan Zone, constituted of the municipalities of Ocotlan, Jamay and Poncitlan which circumscribe Jalisco's Cienega region. The cities and their metamorphosis facilitate the understanding -historical sequential- of the importance of the municipal presidents' decisions starting from the common parliamentary structures.
\end{abstract}

The qualitative methodology implemented across the case analysis, enunciatively concludes with six costs that have to be considered to make the job of the Planning Metropolitan Institute of steering and harmonizing the work of the municipalities. Respecting the sovereignty of each one of them.

Keywords: city; development; democracy; governability; Metropolitan Zone.

\section{Introducción}

En la actualidad los gobiernos municipales enfrentan un contexto sociopolítico que reclama, no solo la permanencia y ampliación de las tareas que tiene a su cargo conforme a los principios y bases fundamentales que lo constituyeron como el ámbito gubernamental más cercano al colectivo social; sino también, asumir los nuevos roles que la geopolítica exige en estos escenarios glocales y de redistribución de competencias. La consolidación del colectivo social obliga a mapas coordinados con escalas de actuación corresponsables para ser capaces de hilar una historia evolutiva de un rediseño de ciudad y el logro del fin último que es el bien común o bienestar social intermunicipal.

Mostrar las bondades de una nueva configuración geopolítica, un gobierno de muchos es transitar a la antesala de una lógica de suma de voluntades (políticas e ideológicas) con altas posibilidades de éxito y la reconsideración de sus formas y modos tradicionales de gobierno, que, sin lugar a duda, han mostrado sus deficiencias de la historia.

Es por ello que la premisa del presente artículo plantea que las metrópolis, nuevas territorialidades y

1 Profesor investigador de la Universidad de Guadalajara adscrito al Centro Universitario de la Ciénega. Politólogo con Doctorado en Educación. Maestro en Filosofía Política y Licenciado en Estudios Políticos y de Gobierno por la Universidad de Guadalajara. Miembro del Sistema Nacional de Investigadores (SNI) y Miembro del Cuerpo Académico Consolidado: UDG-CA 562, Educación, Políticas Públicas y Desarrollo Regional. e-mail: magdielgomez@gmail.com o magdiel.gomez@redudg.udg.mx 
múltiples centralidades de ciudad, pueden ser posibles si los gobiernos municipales asumen los costos de superar los imaginarios con magmas de significación soterrados al hablar en colectivos y redefinir paradigmas que los lleven a constituirse como Ciudades sin Fronteras.

\section{Metodología}

Para el estudio de caso, se usó una metodología cualitativa (recopilación de información, análisis de redes, observación no participativa) que permitieron una construcción de procesos históricos evolutivos de las ciudades hasta las zonas metropolitanas contemporáneas como último estadio de gobernanza territorial, así como la comprensión de los costos de impulsar la política pública de las agendas nodales comunes. La información recabada, contribuyó al debate del bienestar social y la calidad de vida en los grandes conglomerados sociales en Jalisco.

\section{Discusión de resultados}

\subsection{El desarrollo de la metrópoli}

Co-crear, fortalecer, incentivar y desarrollar una metrópoli parte de una lógica de objetivos comunes y un asertivo trabajo para disponer de los mejores instrumentos que detonen buenas prácticas en los gobiernos locales. Es por ello que, el rediseño de ciudad del Siglo XXI debe apostar a impulsar nuevas centralidades que consideren el exponencial incremento poblacional, los problemas de movilidad urbana y las agendas de seguridad pública. Para ello, es necesario que los territorios establezcan dinámicas para trabajar en conjunto, maximizando recursos que beneficien solidariamente una economía social.

Desde hace más de 15 años en Jalisco (México) se trabaja desde lo federal en una agenda que tiene por objetivo propiciar un ecosistema de espacios comunes diseñados para trascender como seres humanos; un conglomerado de ciudades capaces de poner frente a frente a los habitantes para vivir experiencias de diálogo y creatividad, de tal manera que el trazo rescate los valores de confianza y unidad como pilares para el desarrollo integral. Sin duda, los retos de las zonas metropolitanas van más allá de hablar en plural deben suspirar en estadios más elevados de fortalecimiento democrático, así como de una plena representación política a través de mecanismos de participación ciudadana plena y una rendición de cuentas en el uso de los recursos públicos.
Las ciudades se han alejado de ser los espacios para el desarrollo humano, hoy en la cotidianidad se padece vivir en demarcaciones territoriales confinadas al hacinamiento y sobre todo con una alta proclividad para transformarse en caldo de cultivo de patologías psicosociales, se ha tocado fondo cuando se observa el entorno y se percibe que la arquitectura se separó de la política, lo precario de la inteligencia se ha hecho una norma y hoy se atestiguan desarrollos habitacionales de 4 metros lineales de frente y 10 metros de fondo, muy alejados de la lucidez y majestuosidad de visiones arquitectónicas estilo Luis Barragán y sus rabiosos espacios de habitabilidad con áreas verdes.

Las ciudades en descomposición manifiestan una serie de sintomatologías que son factibles de ser abordadas por los especialistas de los territorios, y no necesariamente a los arquitectos, paisajistas o diseñadores, cualquier persona en su sano juicio sabe diferenciar que es toda una proeza poder respirar en las ciudades; que los cotos son feudos de aislamiento; que las casas son las nuevas prisiones por la incapacidad de sumar desde las diferencias a los que menos poseen. Acostumbrados a la parálisis vehicular, a la crítica del vecino y al enanismo servil de mantener la boca cerrada ante las injusticias el ciudadano que se ha ido esculpiendo, boicotea cualquier lógica de trabajo colectivo, solidario e incluyente.

No se puede tapar el sol con un dedo, reza el refrán y el deterioro de la calidad de vida hace que la ciudad se encamine a un precipicio, es alarmante como los hogares se quedan vacíos y hoy solo se asiste al domicilio para mal dormir, pagar las hipotecas de casa y continuar al día siguiente para emigrar a otro municipio en el que se encuentra el lugar de trabajo. Mientras se traslada un ciudadano de un punto a otro se corre el riesgo de perder la vida, debido a que sobrevivir en un territorio minado por la delincuencia es cuestión de suerte. El azar es el eje conductor de aquellos que comparten espacios comunes.

Meditado el esquema anterior, existe un reto para fraguar un futuro aliciente; se debe re entender la ciudad y su ciudadanía con los pies puestos en los terrenos de la proactividad, la imaginación, la innovación y la suma de voluntades que básicamente apuestan a un equipo de hacedores de política y gobierno con liderazgo y corresponsabilidad. Administradores de las no fronteras que sean capaces de dejar de lado las promesas huecas, y conquisten un detallado mapa de homogeneidad territorial. 
No se requiere un plan estratégico para el 2030, ni mucho menos una gruesa obesidad burocrática que planifique sin etapas, o peor aún, que lo haga desde la comodidad de las oficinas y con aire acondicionado. Se requiere de una capacidad de gestión probada y una comunicación con doble vía para fortalecer la confianza mutua entre gobierno y gobernado. Las ciudades necesitan cooperación para avanzar, pero la cooperación ya no es solo de una ciudad aislada, se hace indispensable una red de redes de gobernanza para elevar el discurso a niveles de metrópolis y agendas multiplicadoras de proyectos sostenibles.

Bajo ese contexto metropolitano, se le puede exigir a las democracias contemporáneas, establecer para el desarrollo territorial y, por último, se tendrán como consideraciones finales las nuevas centralidades de ciudad, su visión prospectiva y los mecanismos capaces de superar la inequidad territorial, en lo particular el caso de la Zona Metropolitana 23 constituida por Ocotlán, Poncitlán y Jamay y la conformación de su Instituto Metropolitano de Planeación.

\subsection{Las ciudades y su urbanización}

La mayoría sueña con una ciudad más armónica, transitable, sustentable y sobre todo segura, pero la realidad dista mucho de los sueños que se puedan tener. Hoy más que nunca, la sociedad es testigo de cómo han evolucionado las ciudades y también los grandes problemas que traen consigo. Para mencionar un ejemplo: en la actualidad se pierden 4 años de vida en el tráfico, aniquilando el $30 \%$ de productividad, promoviendo la obesidad y restando 3 horas diarias al sueño, a la diversión y convivencia familiar. Así lo señala un estudio de la Casa Consultora Riva Group y el Índice de Tráfico 2018 que realiza TomTom.

Los especialistas en construcción de ciudad aseguran que de seguir así en 10 años (2030), se estará ante un colapso irreversible y el mismo calentamiento global, las enfermedades derivadas del caos citadino y la ingobernabilidad del espacio público fulminarán de tajo a la humanidad. Por ello, atendiendo a los que saben, se han constituido institutos focalizados para resolver, de alguna manera, esta apocalíptica visión. Los institutos metropolitanos de planeación (quizá no sean la solución completa, pero coadyuvan en impulsar proyectos para hacer frente al reto de las megalópolis). En voz de Gutiérrez Padilla se deben "resolver los problemas que hoy nos caracterizan como ciudades 4D (dispersas, distantes, desconectadas y desiguales) y dar paso a las condiciones necesarias para evolucionar rumbo a una Ciudad C3E" (R. Gutiérrez comunicación personal, 23/06/2018).

La Ciudad C3E: es aquella ciudad que se caracteriza por estimular comunidades Cercanas, Compactas, Conectadas y Equitativas. Un reto que los institutos metropolitanos de planeación en México lo están confeccionando en un rediseño de gobiernos municipales para trabajar desde una interrelación funcionalista.

Los nuevos mapas metropolitanos generan los algoritmos para ordenar operaciones sistemáticas que permitirá hallar la solución a los problemas de las ciudades hipertrofiadas, y van más allá de la tradición de pactar desde la comodidad y autonomía del Artículo 115 constitucional.

Administrar una ciudad no es cosa fácil, habrá que pensar cómo las administraciones municipales elevan los debates para sostener las bondades de una urgente redensificación de territorios y sobre todo la reforestación intrínseca que conlleva dotar de pulmones verdes a las selvas de concreto, eso sí con una purga burocrática para facilitar los procesos.

Aunado a ello, se hace vital que los ordenamientos de territorio se encuentren regulados y socializados para propiciar la inversión de acuerdo con el vocacionamiento del suelo. Se requiere entonces, armonización de nuevas centralidades tendientes a promover el desarrollo económico y resiliente. Aunque pareciese que esto está en incipiente avance, se debe señalar que la tendencia de las ciudades-medias es emigrar a un modelo de metrópoli que aglutine el mayor número de proyectos viables, pertinentes, resilientes y transversales, partiendo de su particular potencial geográfico.

Por mencionar el caso que nos ocupa: Ocotlán desde 2009 es reconocida como Zona Metropolitana 23 por parte de la Federación, en la actualidad el reto es redefinir el contexto geopolítico y emigrar a una región metropolitana y con los desafíos que ello implica. Sin duda, ser región metropolitana facilitará el fondeo de proyectos transversales para beneficio de la sociedad. Traducido en pocas palabras: inversiones de cara al trabajo conjunto de los municipios, pero no todo es miel sobre hojuelas, hay costos intrínsecos de la participación colectiva municipal.

El tiempo cuenta que para ejercer un buen liderazgo se hace imprescindible una buena estructura con metas definidas y los institutos metropolitanos de planeación han realizado asignaturas que se ha- 
cen tangibles unas rutas de trabajo que incentiven la configuración de metrópolis policéntricas, equitativas y solidarias, con una reestructuración de agendas transversales enfocadas a ejercer nuevas facultades de forma progresiva, coordinada y bajo una óptica de corresponsabilidad en la implementación de políticas públicas con metas claras como la disolución de fronteras intermunicipales y un reequilibrio central periférico.

Lo anterior obliga a realizar una aproximación semántica sobre la ciudad, entendida esta como un concepto que puede definirse a partir de la organización de un cuerpo social complejo. Para el investigador Ugo Pipitone (2003) sería: "una mezcla de distintos intereses y visiones que conviven en una unidad en casi permanente conflicto consigo misma. En sus edificios, en el diseño de calles, mercados y palacios se va definiendo una nueva racionalidad en la cual lo cercano y lo lejano se entremezclan, la seguridad y la aventura establecen un nuevo equilibrio, la riqueza y el poder adquieren otras formas y construyen nuevas relaciones entre sí" (Pipitone, 2003, p. 21).

Bajo esta lógica se puede reafirmar lo que al respecto aborda el investigador José Luis Lezama que señala que la ciudad es el lugar en donde "se concentra la creatividad y da lugar a los más altos productos de la acción humana..., en la ciudad se expresa la sociedad en su conjunto, tanto las relaciones de producción que constituyen la base económica, como la superestructura; la ciudad proyecta sobre el terreno a la totalidad social; es economía, pero también es cultura, instituciones, ética, valores, etc. Por tanto, la ciudad brinda al analista la posibilidad de reconstruir a la sociedad en su conjunto" (Lezama, 2010, p. 252).

En una ciudad media la capacidad decisional para hablar de habitabilidad y desarrollo radica en la pertinencia de iniciativas que incluyan ejes transversales y horizontales para generar dinámicas de armonización con "derechos de tercera y cuarta generación”. En particular, sentar las bases para que se dé el compromiso dialéctico de significaciones sociales que confluyan en un solo punto de encuentro: calidad de vida y bienestar social.

Jaime Sobrino (2019) es más acucioso al referirse a una derivada de las ciudades y es el concepto de urbanización que orilla a repensar el binomio ciudad-urbanización como variables codependientes que se mezclan al momento de fijar agendas y trazar los planes de desarrollo y la metas de edificación para comprender el "proceso de cambio cuantitativo en la distribución espacial de la población hacia su mayor concentración en zonas urbanas, cambio que va aparejado a transformaciones cualitativas en los estilos de vida de la población" (p. 35).

El Cuadro $N^{\circ} 1$ presenta los componentes inherentes a la ciudad en su acepción filosófica y del otro lado los elementos que deberán observar las metrópolis constituidas a partir de demandas ciudadanas más recurrentes.

\section{Cuadro $\mathrm{N}^{\circ} 1$ Elementos Metro-ciudadanos}

\begin{tabular}{|c|c|c|}
\hline $\begin{array}{c}\text { Ciudad:componentes } \\
\text { económicos, sociales y } \\
\text { culturales }\end{array}$ & $\begin{array}{c}\text { Metrópoli:gestión del territorio } \\
\text { urbano interconectado y } \\
\text { homogeneizado }\end{array}$ \\
\hline Accesibilidad & Suelo urbano & Vivienda \\
\hline Adaptabilidad & Equipamiento & Movilidad \\
\hline Gobernabilidad & $\begin{array}{c}\text { Policía } \\
\text { Metropolitana }\end{array}$ & Medio ambiente \\
\hline Interconectividad & \multicolumn{2}{|c|}{ No Fronteras } \\
\hline
\end{tabular}

Fuente: elaboración propia.

Acercar ciudad-urbanización-metrópoli, tendrá por resultado un coctel propicio para hablar de áreas inteligentes o ciudades inteligentes en lo individual; $\mathrm{y}$, en lo colectivo, metrópolis no difuminadas con rediseños pertinentes. Porque la ciudad es un entramado complejo es indispensable comprender que la integración de sus elementos que se orientan al máximo desarrollo y las aspiraciones plurales del común de los ciudadanos.

\section{Figura $\mathrm{N}^{\circ} 1$ Integración de objetivos orientados al desarrollo}

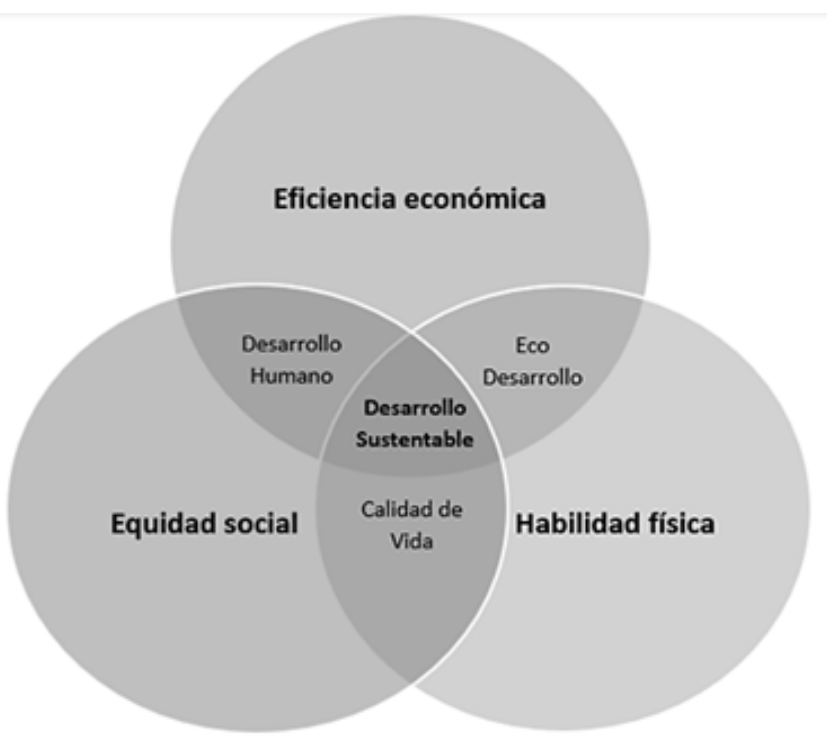

Fuente: Requena, C. (2016). 
De la figura anterior se pueden referenciar las intersecciones de un espectro enfocado en la calidad de vida; desarrollo sustentable; desarrollo humano y eco-desarrollo serán entonces, las interconexiones consensuadas que incluye a todos los implicados. Integración de objetivos cómplices de las variables de economía y equidad social; hoy comúnmente llamados Nodos de Desarrollo Económico Social y Solidario (NODESS).

\subsection{Las Zonas Metropolitanas en México}

La ciudad para el bienestar multidimensional deberá transitar de lo local hacia lo global, es decir de municipio a intermunicipalidad. Y, a razón de clarificar esta aseveración, se hace indispensable un recorrido histórico para dar un amplio contexto de qué época datan las primeras acciones de pensamientos sin fronteras. Para ello, es fundamental señalar que los historiales sobre las metrópolis proceden desde la celebración de la Conferencia Mundial sobre los Asentamientos Humanos de la que se desprende la Declaración de Principios y Compromisos del Foro Mundial de Parlamentarios para el Hábitat, conocido también como "Declaración de Estambul Hábitat II" en el que se establecen los principios generales internacionales sobre los asentamientos humanos en el mundo y en lo particular lo referente a las metrópolis y megalópolis del mundo.

En América Latina la organización espacial posee una lógica urbana que data desde la conquista europea del Siglo XIX.

\section{Cuadro N² Períodos de transformación metropolitana}

\begin{tabular}{|c|c|}
\hline $\begin{array}{c}\text { Período } \\
\text { I }\end{array}$ & $\begin{array}{c}\text { Nombre } \\
\text { Portugal }\end{array}$ \\
\hline II & $\begin{array}{c}\text { La ocupación de América Latina por España y } \\
1860-1917\end{array}$ \\
\hline III & Las ciudades de los terratenientes \\
\hline $1950-1980$ & Período de la Ciudad Industrial \\
\hline IV & Período de Globalización \\
\hline Siglo XX-XXI & \\
\hline
\end{tabular}

Fuente: elaboración propia.
Según la estudiosa sobre las urbanizaciones en Iberoamérica, Amalia Geraiges de Lemos existen 4 grandes períodos de transformación de los asentamientos humanos que definen los derroteros de las Zonas Metropolitanas en México:

- En México actualmente existen 74 zonas metropolitanas reconocidas. En el caso de Jalisco sólo hay 3 reconocidas: Guadalajara: Zapopan; Tlaquepaque; Tonalá; El Salto; Tlajomulco; Zapotlanejo; Juanacatlán e Ixtlahuacán de los Membrillos.

- Puerto Vallarta: Bahía de Banderas.

- Ocotlán: Poncitlán-Jamay. (Ameca con altas posibilidades de constituirse una vez que las gestiones burocrático administrativas se lleven a cabo y que las gestiones legislativas).

La Secretaría de Desarrollo Social (SEDESOL, 2012) y el Consejo Nacional de Población (CONAPO) elaboraron en 2012 un documento denominado Catálogo-Sistema Urbano Nacional 2012, en el que delimitaron las aglomeraciones urbanas de México en 2010 y estimaron sus poblaciones para 1990 y 2000.

Estas aglomeraciones urbanas se dividieron en tres grupos:

a) Centros Urbanos o ciudades con 15 mil o más habitantes que no reúnen características de conurbación o Zona Metropolitana.

b) Conurbación o conformación urbana resultado de la continuidad física entre dos o más localidades geoestadísticas o centros urbanos, que constituyen una sola unidad urbana de por lo menos 15 mil habitantes, pudiendo ser intermunicipales o interestatales cuando su población es de entre 15 mil y 49,999 habitantes e intramunicipales si superan este rango de población.

c) Zona Metropolitana o agrupación en una sola unidad altamente interrelacionada funcionalmente, así como centros urbanos mayores a un millón de habitantes aunque no hayan rebasado su límite municipal, y centros urbanos de las zonas metropolitanas transfronterizas mayores a 250 mil habitantes" (Sobrino, 2019, p. 45). 
Figura N² Evolución de los espacios urbanos a partir de la cantidad poblacional

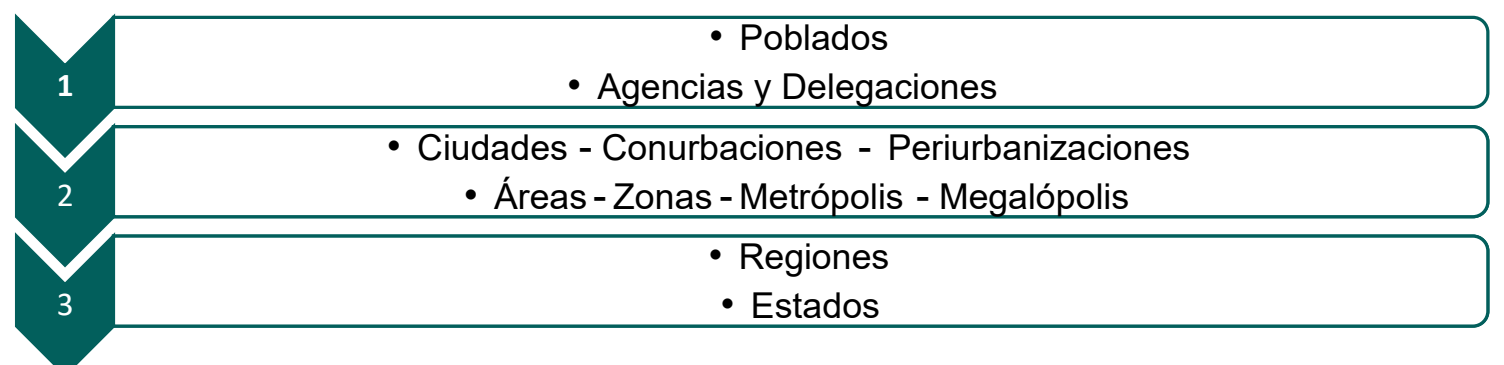

Fuente: elaboración propia.

La constitución de las zonas metropolitanas entra bajo la lógica de la política para configurar criterios que busquen distribuir pesos y contrapesos para la representación de los intereses de cada región en que se divide México. Los reglamentos; leyes y órganos colegiados que regulan la coordinación; administración, el marco orgánico y dogmático son:

- Plan Nacional de Desarrollo.

- Plan Estatal de Desarrollo y Gobernanza.

- Plan Municipal de Desarrollo.

- Ley General de Asentamientos Humanos, Ordenamiento Territorial, y Desarrollo Humano.

- Ley de Coordinación Metropolitana.

- Plan de Ordenamiento Territorial Metropolitano.

- Programa de Fomento a la Planeación Urbana, Metropolitana y Ordenamiento Territorial.

- Reglamento de Desarrollo Urbano.

- Consejo Metropolitano.

- Instituto Metropolitano de la Planeación.

- Comisión de Asuntos Metropolitanos. -Congresos Federal y Local.

- Congreso del Estado garante y aval de configuración de Zonas Metropolitanas.

Políticamente correcto, una metrópoli es: el conjunto de municipios que por colindancia geográfica y características (más o menos) homogéneas propician ejes que facilitan el desarrollo económico, social, político de una comunidad, o en voz de Jaime Sobrino una Zona Metropolitana es un conglomerado terri- torial que incluye municipios completos en los que existe una ciudad central y asentamientos humanos unidos físicamente a ésta, o que mantienen estrechos vínculos con dicha ciudad central (Sobrino, 2019, p. 45).

Es indispensable discutir el modelo de gestión de metrópoli a partir de los siguientes elementos que deberán gravitar para la edificación de fórmulas administrativas con jurisprudencia metropolitana sin perder la autonomía y acuerdos de cooperación individual que se sumen a la traza urbana resiliente.

La Figura N ${ }^{\circ} 3$ define simbólicamente al menos seis elementos que ontológicamente puntualizan las metrópolis.

\section{Figura №3 Configuración Ontológica Metropolitana}

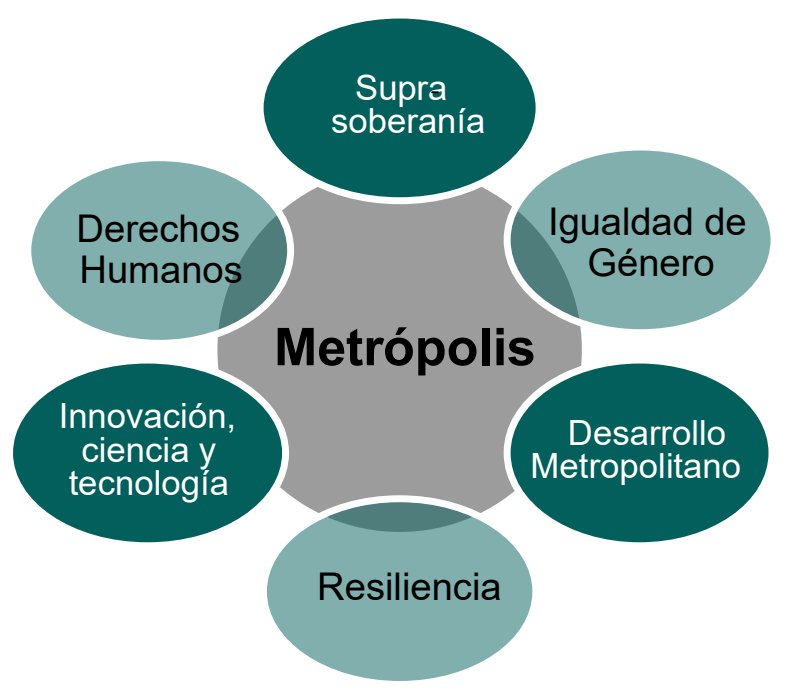

Fuente: elaboración propia.

En esta constelación de variables, las metrópolis engendran una rica gama de imaginarios que exigen una dosis de pragmatismo para trazar la carre- 
tera en la que viajará el desarrollo de aldeas con metas colectivas.

La hiperactividad bajo este nuevo esquema de suma de ciudades, será el elemento clave a vencer, debido a que la velocidad en que viajará la toma de decisiones nubla la capacidad de servidores públicos de media jornada y semana inglesa.

El repertorio de retos a solventar sería infinito, pero en este enfoque de ver el vaso "medio lleno" se deberá apostar a que el servicio profesional en los institutos metropolitanos sea seleccionado bajo un estricto esquema metodológico de experiencia y bases epistemológicas. Situación que en ningún momento se ha debatido al abordar temas de construcción de ciudad y espacios metropolitanos.

\subsection{Zona Metropolitana 23. Ocotlán-Jalisco-Mé- xico. Las nuevas centralidades}

La Zona Metropolitana de Ocotlán (ZMO) es un claro ejemplo de esta nueva lógica de hacer política a lo largo del territorio de la Ciénega, de su integración social y económica, así como su derecho a ecosistemas de sustentabilidad y agendas verdes.

Ocotlán, Poncitlán y Jamay, apuestan a ver reflejada para el 2020 una homogeneidad de su crecimiento y conurbaciones. Sin embargo, solo dos de los municipios (Ocotlán-Poncitlán) tienen los instrumentos legales para establecer convenios de cooperación y coordinación que se plantean bajo esquemas de participación ciudadana plena, gobernanza, equidad de género y alineación a los Objetivos de Desarrollo Sostenible en sus planes de desarrollo municipales. Por tanto, la cooperación y coordinación intermunicipal con el rezago de Jamay es restringida. Entender los incentivos específicos que los actores políticos tienen para adoptar e implementar mecanismos de cooperación intermunicipal, exige que todo el andamiaje jurídico se armonice y en una lógica de contar -incluso- con comisiones edilicias que se generen exprofeso para la lógica de participar en hipotética zona metropolitana.

En la configuración de la ZMO, el órgano que se ha convertido en el engrane articulador de la autoridad local es la Junta de Gobierno que se constituye por los presidentes municipales en turno y le rinden cuenta al gobernador del Estado. Las presidencias de la Junta de Gobierno de la zona metropolitana - para el caso que nos ocupa- tendrán una duración de seis meses y será rotativa; se coordinarán con los regidores de las comisiones edilicias correspondientes a la construcción de ciudad y harán acuerdos de proyección y desarrollo con el director del Instituto Metropolitano de Planeación (IMEPLAN) de Ocotlán, que fungirá como el más alto representante de los trabajos de gabinete con los tres equipos de los que configuran la zona.

Para el banco de proyectos y la viabilidad de ellos, harán enlace con los institutos de planeación municipal o las direcciones de ordenamiento territorial y coordinación de obras públicas y planeación con una supervisión permanente de tres órganos colegiados en donde participarán las instituciones de educación superior, la iniciativa privada y un sector de la sociedad civil.

En todo momento el IMEPLAN-Ocotlán, observará los trabajos de desarrollo urbano y someterá a consulta con las diferentes coordinaciones lo relativo en materia de planeación, desarrollo urbano y vivienda, así como movilidad, seguridad pública, agendas verdes y resilientes y la calidad en los servicios públicos.

Los alcances del IMEPLAN-Ocotlán gravitarán en dos sistemas de poder que se interrelacionan con la comunidad (al exterior) y la cocreación gubernamental (al interior) ambos sistemas organizacionales coincidirán en una minuciosa evaluación de los diversos programas de desarrollo urbano y vivienda; dictaminación en lo referente a reservas, usos y destinos de áreas y predios; rescate de espacios públicos como programas gubernamentales; la evaluación de obras de infraestructura y equipamiento urbano de importancia regional, respetando los vocacionamientos de cada una de las municipalidades; pero sobre todo decidir en aquellos asuntos que tengan un gran impacto y se encuentren alineados a los ODS para reducir las diferencias de puntos de vista en relación al tratamiento de una política pública municipal, entre otros.

Por una parte, la Zona Metropolitana 23 se ha gestado a partir de una suerte de pasos burocráticos-administrativos que datan desde 2009 y han dejado evidencias de un trabajo local de municipalidades y el aval de la federación desde la Cámara de Diputados Federal para incluir en las zonas metropolitanas del país los trabajos de planificación integral metropolitana impulsada por la alianza Ocotlán, Poncitlán y Jamay. En el 2012 se inyectaron recursos por el monto de los 33 millones de pesos que se distribuyeron de manera consensuada para la construcción de 
un parque metropolitano que da vida a un espacio de recreación y fortalecimiento de tejido social (enclavado en Ocotlán) con resultados incipientes debido a la falta de inyección presupuestal para escalar el proyecto hacia dimensiones acordes al trabajo intermunicipal.

Para el año de inicio gubernamental -2015- la distribución presupuestal difícilmente rebasó los 11 millones de pesos y la merma presupuestal en la configuración de trabajos metropolitanos dejaba en evidencia la perniciosa intención de los actores políticos sobreponiendo sus intereses electoreros por las ganancias de planificación y construcción de nuevas centralidades a largo plazo. En ese trienio 2015-2018 la promoción de consensos en los objetivos del crecimiento metropolitano, dejó de lado la participación ciudadana y la presentación de proyectos ante la Comisión de Federalismo y Desarrollo Municipal canceló los apoyos para los estados y municipios.

Es hasta junio de 2019 cuando se reconoce por parte de la Federación y el Estado de Jalisco la Zona Metropolitana de Ocotlán y con ello, los trabajos al interior de los municipios para la miscelánea jurídica han podido convertirse en bancos de estudios e información sobre problemas regionales y en excelentes espacios para debatir problemas inherentes de un nuevo gobierno intermunicipal.

En ausencia de una lógica de gestión funcional, para que los municipios puedan hacer uso eficiente y eficaz del desarrollo urbano la puesta en marcha del IMEPLAN ha permitido una tarea más profesional del desarrollo urbano en el Estado. A saber, Jalisco cuenta con tres zonas metropolitanas y la más reciente es la que se encuentra enclavada en la Región Ciénega. Es decir, la puesta en marcha de un Instituto Metropolitano de Planeación y la lógica de trabajo intermunicipal han creado un foro para que diversos actores políticos se convirtieran en emprendedores de políticas públicas de cooperación y coordinación en las áreas metropolitanas.

Esta puesta en marcha de una nueva multicentralidad de ciudad nace con el propósito de eliminar la centralización del poder y abre la posibilidad de incluir la participación ciudadana para la toma de decisiones, recordando que en un gobierno metropolitano la idea de fragmentación de los gobiernos locales es un tema que será recurrente en cada administración que llegue para sumar esfuerzos en lo colectivo. Esta postura de multicentralidad está fuertemente ligada al concepto de gobernanza.
El nuevo esquema busca crear estructuras de decisión que favorezcan la colaboración entre gobiernos locales de manera pertinente para cada región y servicio. Esto se ha considerado como una forma alternativa de hacer funcionar el federalismo en la ausencia de un régimen federal eficiente que centraliza decisiones y ejecuta en un modelo jerárquico vertical.

\section{Conclusiones}

Grosso modo se puede afirmar que:

a) Los problemas que pudiesen presentar estas nuevas estructuras de articulación gubernamental son causados por la falta de coordinación.

b) Los problemas de coordinación pueden ser más fáciles de resolver porque solo requieren del diseño y adopción de instituciones que provean de puntos focales.

c) Para el caso de la ZMO pareciera que se avecinan al menos dos nuevas tareas: la incorporación del municipio de La Barca; Tototlán y Zapotlán del Rey que han generado prácticas gubernamentales sobre cómo y hacia dónde debe crecer la ciudad con calidad, gobernanza y resiliencia.

d) Enfrenta claros impedimentos ya que la transversalidad de proyectos para ser considerados en etiquetas presupuestales o incentivos de inversión federal no son garantizables.

e) La cooperación para el desarrollo no deja de ser una meta, discurso alejado de la real política.

f) Sumado a lo anterior puntualizan los costos de transacción para incentivar el cooperativismo intermunicipal que resultan muy elevados:

- Costo de lobbying: tiempo invertido de horas-hombre dedicados a los procesos de negociación de un acuerdo intermunicipal, casi siempre se presentan en las presidencias de las comisiones edilicias.

- Costo de la información: asociados con la recolección de datos e información de carácter público, así como los sondeos de opinión sobre los proyectos de beneficio para la comunidad. Encuestas y apertura de base de datos, ya sea en archivos históricos o electrónicos.

- Costo de partido: costos que representa para los presidentes municipales negociar con sus pares emanados de otra ideología política y la defensa 
de sus espectros ideológicos de carácter electoral.

- Costos legislativos: asociados a la repartición de los beneficios por fracción edilicia y la aprobación en el pleno de los cabildos para aprobar un reglamento o proyecto, con una alta volatilidad de ser chantajeados para voto a favor de dictamen o acuerdo.

- Costo de cuenta pública: asociados con las cuentas contables, licitaciones, responsables de proyectos y contralorías ciudadanas. Se parte de una lógica de la total desconfianza entre los participantes.

- Costo de partida 1000: costos que deberán destinar para la ampliación de la nómina, la homologación salarial y las prestaciones de los titulares del IMEPLAN y su estructura burocrática-administrativa.

EI IMEPLAN, en efecto deberá jugar un papel protagónico como organismo garante de armonización intermunicipal con una lógica de agenda pública e implementación de políticas con enfoque económico, social y solidario. El reto de las nuevas centralidades de ciudad y sus alcances radica en entender mejor los incentivos que enfrentan en su función y que les motivan o desincentivan a buscar acuerdos colaborativos.

Por tanto, la cooperación resiliente debe lanzar algoritmos no sólo de intereses económicos, sino también con espectros amplios de participación ciudadana y sus alcances, costos y beneficios para los actores locales.

Para finalizar, el trabajo en red y sus factores endógenos deberán elevar discusiones a fin de alcanzar y adoptar acuerdos de cooperación multicéntricos, intermunicipales, pentahélices y sustentables.

\section{Referencias bibliográficas}

- Geraiges, De Lemos Amalia Inés. (2004). "La Globalización y sus impactos en las áreas urbanas en América Latina", Revista Anales de Geografía. Universidad Complutense de Madrid. España.

- Gutiérrez Padilla, R. (2018). "Ciudad C3E" Entrevista Director IMEPLAN Guadalajara.
- Índice Tom-Tom. (2018). Disponible en: https:// www.tomtom.com/en_gb/traffic-index/

- Pipitone, Ugo. (2003). "Ciudades, Naciones, Regiones. Los espacios institucionales de la modernidad". Ed. Fondo de Cultura Económica. México.

- Requena, C. (2016). CiudadMx 360. Modelo de ciudad inteligente. Ed. LID. México.

- Sobrino, J. (2019). Desarrollo urbano y metropolitano en México. Ed. Colegio de México. México.

- Lezama, José Luis. (2010). "Teoría social, espacio y ciudad” Editorial El Colegio de México. 